\title{
Caracterización y Evaluación Biogeográfica a través del Método Lanbioeva de los Bosques de Quercus Petraea del País Vasco y Navarra (Península Ibérica)
}

\section{Characterization and Biogeographic Evaluation through the Lanbioeva Method of the Forests of Quercus Petraea of the Basque Country and Navarre (Iberian Peninsula)}

\author{
Pedro José Lozano-Valencia \\ pedrojose.lozano@ehu.eu 0000-0002-1345-5704 \\ Rakel Varela-Ona \\ rakel.varela@ehu.eu (10000-0001-5079-0627 \\ Asier Lozano-Fernández \\ lozanoasier6@gmail.com @ 0000-0002-3013-4929 \\ Guillermo Meaza-Rodríguez \\ guillermo.meatza@gmail.com @ 000-0003-0705-2631
}

Euskal-Herriko Unibertsitatea, Letren Fakultatea. C/Tomás y Valiente, s/n. 01006 Vitoria-Gasteiz.

\section{INFO ARTÍCULO}

Recibido: 04-08-2020

Revisado: 16-12-2020

Aceptado: 24-12-2020

\section{PALABRAS CLAVE}

\section{Quercus petraea}

Filiación corológica

Estatus

Diversidad específica

Evaluación biogeográfica

País vasco

Navarra

\section{KEYWORDS}

Quercus petraea

Chorological affiliation

Status

Specific diversity

Biogeographical evaluation

Basque country

Navarre

\section{RESUMEN}

Se caracterizan y evalúan los bosques de Quercus petraea del País Vasco y Navarra. Tres son las ubicaciones elegidas: sur de Bizkaia, sur de Guipúzcoa y norte de Navarra. Se acomete un inventariado de 10 parcelas por cada ubicación y se analizan diferentes características: diversidad específica, filiación corológica, estatus de las especies y aplicación del método LANBIOEVA. Estos robledales son muy escasos dentro de la Península Ibérica y cuentan con cortejos donde dominan también las plantas escasas. En estos bosques, en general, dominan las filiaciones eurosiberianas o euroasiáticas, atlánticas y de transición entre el mediterráneo y el atlántico. Las formaciones de Navarra se configuran como las más diversas, seguidas por las de Guipúzcoa y las de Vizcaya. La evaluación biogeográfica da lugar a altos valores (por encima de los 1.200 puntos) para los tres robledales, pero superiores en Pikandi (Gipuzkoa) y Garralda (Navarra) y más modestos en Garrastatxu (Bizkaia).

\begin{abstract}
The forests of Quercus petraea of the Basque Country and Navarre They are characterized and evaluate. Three are the locations chosen: south of Vizcaya, south of Guipuzcoa and north of Navarra. An inventory of 10 plots is undertaken for each location and different characteristics are analyzed: diversity, chorological affiliation, species status and application of the LANBIOEVA method. These oak forests are very scarce and have courtships where scarce plants also dominate. In these forests, dominate, in general, eurosiberian or Eurasian, Atlantic and transitional affiliations between the Mediterranean and the Atlantic. The oak forests of Navarra are configured as the most diverse, followed by Guipuzcoa and Vizcaya. Biogeographic evaluation results in high values for the three formations but higher in Pikandi and Garralda and more modest in Garrastatxu.
\end{abstract}




\section{INTRODUCIÓN}

El roble albar [Quercus petraea (Matt.), Liebl.], a diferencia de su congénere el carballo (Quercus robur L.), es una especie escasa en la Península Ibérica. Ambos presentan un aspecto bastante parecido, pero muestran algunas diferencias morfológicas: justamente al contrario del carballo, el roble albar cuenta con hojas de peciolo largo (de hasta 2,5 cm) y bellotas sentadas sobre la rama. El roble albar muestra cierta pilosidad en el envés de la hoja, especialmente en las axilas de las nerviaciones, mientras que en el segundo son totalmente glabras. Por otra parte, Q. petraea es de porte más alto y monumental que Q. robur, aunque esto puede ser debido a la gran presión que este último ha sufrido por parte del ser humano; tanto que es difícil encontrar en la actualidad bosques maduros y bien desarrollados. El hecho de que el roble albar se sitúe lejos de los asentamientos urbanos más masificados, en sistemas montañosos relativamente inaccesibles y, muchas veces, protegidos ha podido dar lugar a una mayor madurez de sus escasas masas.

El albar puede alcanzar un porte de hasta $35 \mathrm{~m}$, cuenta con una copa bastante regular, aovada o/y redondeada y un tronco de corteza grisácea o parduzca pero muy hendida por grietas más profundas que las que presenta el carballo. Las hojas son alternas, simples y con el margen lobulado, de contorno largamente obovado. La bellota es también ovoide y el cascabillo de la misma muestra numerosas escamas de forma triangular u ovada (López, 1982). Florece más tardíamente que el carballo, en la transición entre los meses de abril a mayo, y suele enraizar en suelos más secos y menos profundos y estructurados que $Q$. robur. $Q$. petraea se adapta perfectamente a suelos con gran pedregosidad -incluso verdaderos litosoles- y su rango altitudinal oscila entre los 500 y los 1.800 m (López, 1982).

Su distribución corológica abarca el sur, centro y oeste de Europa y Asia occidental. En la Península Ibérica aparece de forma muy dispersa, en manchas relativamente pequeñas, poco extensas, dentro de su mitad septentrional. No obstante, falta en Galicia y desciende hasta el sistema central (Guadarrama, Somosierra, Ayllón, El Paular, etc.), con continuación hacia el este por la serranía de cuenca (sierra de Valdemeca), donde alcanza su límite meridional (Blanco et al., 1997).

Desde hace unos años se asiste a una cierta controversia en relación a la correcta identificación de la especie (Kremer et al., 2002), puesto que, en muchos casos, ambos Quercus presentan alto grado de hibridación, lo que dificulta mucho su adecuada individualización (Muir et al., 2001). Kremer et al. (2002) determinaron un patrón de diferenciación que se centra en medir la distancia entre el borde del primer y segundo lóbulo de la hoja con respecto al nervio central. También toman en cuenta otros parámetros relacionados con la venación o la estructura de los estomas. Es por ello que hay que extremar el cuidado a la hora de la separación de las dos especies.

También se asiste a una formulación de hipótesis acerca de la evolución de determinadas formaciones, en concreto la relación existente entre la progresiva reducción de las masas forestales de $Q$. petraea y la inversamente proporcional progresión de Fagus sylvatica L. (Jalut, 1988; Peñalba, 1994; Sánchez-Goñi \& Hannon, 1999). Por ello, según Carrión et al. (2000) se podría considerar a las masas de Q. petraea como relictos de otras condiciones y épocas, de manera que en la actualidad se encontrarían en franco retroceso frente al haya que seguiría compitiendo y desplazando al primero.

Además, en este tipo de trabajos diacrónicos también se ha investigado la importancia que ha podido tener el ser humano y sus actividades en la pérdida de muchas masas de planifolios, entre ellos el roble albar, en beneficio de especies más plásticas y, sobre todo, oportunistas como el haya, que pueden reaccionar mejor ante los impactos antrópicos colonizando estos espacios y generando otras manchas secundarias diferentes a las preexistentes (Pèlach et al., 2007 y 2011; Gassiot et al., 2014).

El presente trabajo pretende aportar una caracterización de las distintas manchas de Q. petraea en el área considerada para constatar diferencias significativas en torno a cuestiones como el cortejo de cada una, su diversidad específica, sus estructuras, filiaciones corológicas de los taxones que las integran o el estatus de cada uno, amén de diagnosticar el valor de cada una de ellas. El ámbito de estudio abarca las comunidades autónomas del País Vasco y Navarra. En este ámbito geográfico apenas perviven florestas de roble albar de remarcable extensión superficial, pues no es habitual encontrar al robledal albar formando masas puras, sino salpicando otros tipos de bosques o hibridado con otros congéneres; fenómeno que, además de a su 
carácter relíctico, se debe a su peculiar posición bioclimática en el tránsito entre el piso colino y el montano o, lo que es lo mismo, en la banda ecotónica altitudinal que conecta los robledales de Q. robur, en cotas inferiores, y los hayedos de F. sylvatica, en cotas superiores.

Otro objetivo pasa por valorar biogeográficamente estos bosques mediante la metodología LANBIOEVA (Landscape Biogeographical Evaluation) para obtener datos parciales de variables tan interesantes como los valores fitocenótico, territorial, mesológico, estructural, patrimonial y cultural; $y$, de la misma forma, determinar el grado de amenaza que pesa sobre ellos. A partir de los valores parciales se obtienen resultados válidos para una correcta protección, gestión y ordenación de estos bosques. No obstante, también se obtendrán valores globales, como el interés de conservación o la prioridad de conservación, que pueden ser tenidos en cuenta como valores finalistas, sintéticos, que proveen al tomador de decisiones de buenos datos para la correcta gestión de las masas estudiadas.

De esta forma, parece lógico pensar que, si nos encontramos con una formación relicta y en franca regresión, debería encontrarse especialmente protegida. Precisamente, la metodología LANBIOEVA sirve para determinar el grado de protección necesario para estas masas a la vista de la reducción que ha sufrido en los últimos 10.000 años. La aplicación de este método puede arrojar luz sobre el estado de estos emplazamientos concretos y observar cuáles son sus amenazas y fortalezas para su correcta gestión y/o conservación, de manera que es una buena aproximación al riesgo que presentan.

A lo largo y ancho del territorio estudiado se han detectado y prospectado diversas facies de robledal albar, algunas de ellas tan excepcionales y llamativas como la que aúna en el sotobosque elementos autoecológicamente tan dispares como Buxus sempervirens L. y Vaccinium myrtillus L. (Garralda), o aquella que pone en contacto esta formación con la del encinar cantábrico en un ecotono de gran relevancia e interés biogeográfico (Garrastatxu y Las Encartaciones).

Este trabajo se centra en tres localizaciones concretas. La más occidental (Garrastatxu), se ubica en territorio vizcaíno limítrofe con Álava -en el sector sudoccidental del Parque Natural del Gorbea-, y se desarrolla entre las cotas 425 y 610 m intermediando la vegetación de ribera o el encinar cantábrico de las cotas bajas con el hayedo de las altas (Mapa 1, n 3). La segunda es la de Pikandi, que tapiza la abrupta vertiente guipuzcoana de la Sierra de Aizkorri, en las inmediaciones del pantano de Barrendiola, entre los 550 y los $800 \mathrm{~m}, \mathrm{y}$ pone en contacto los bosques colinos de roble carballo de la parte baja con los extensos hayedos de la zona alta (Mapa 1, n 5). La tercera, que se sitúa en las inmediaciones de la localidad navarro-pirenaica de Garralda, casi en la frontera con Francia, se desarrolla entre las cotas 700 y 900 m, enlazando los bosques de $Q$. humilis Miller de las partes más bajas con los de F. sylvatica-Abies alba Miller de las más altas (Mapa 1, n 10).

\section{ANTECEDENTES TEÓRICOS}

En la zona de estudio, Q. petraea tiende a establecerse a altitudes superiores a Q. robur, que ocupa el piso colino. Concretamente, en el tránsito entre este último y el montano (por encima de los 500-600 m.), donde ha de compartir territorio y ecosistema con F. sylvatica. Es este un tema de indudable relevancia, ya que alimenta la controversia acerca de qué tipo de evolución diacrónica han experimentado las dos especies y, sobre todo, cuál ha sido la evolución de sus metapoblaciones a lo largo de los últimos 10.000 años (Blanco et al., 1993; Streiff et al., 2003). Todo parece indicar que F. sylvatica se encontraría, originalmente, acantonada en Los Cárpatos durante el último máximo glaciar y que, desde estos refugios, una vez que la influencia de la masa de hielo comenzó a decrecer fue colonizando nuevos espacios hacia el oeste, hasta llegar a la Península Ibérica (Bennet, et al., 1991). Sin embargo, según estos mismos autores, es posible que, aunque Los Cárpatos fueran el núcleo original de dispersión, durante la última glaciación pudieran haber existido pequeños refugios más o menos puntuales en Los Balcanes, los Alpes y las montañas italianas. En cualquier caso, todo parece indicar que $F$. sylvatica llega a la Península Ibérica por el este, a través del Pirineo oriental hace 4.500 años (Jalut, 1988; Peñalba, 1994; Sánchez-Goñi \& Hannon, 1999) y a la Cordillera Cantábrica hace entre 4.000 y 3.500 años (Peñalba, 1994; Sánchez-Goñi \& Hannon, 1999). 


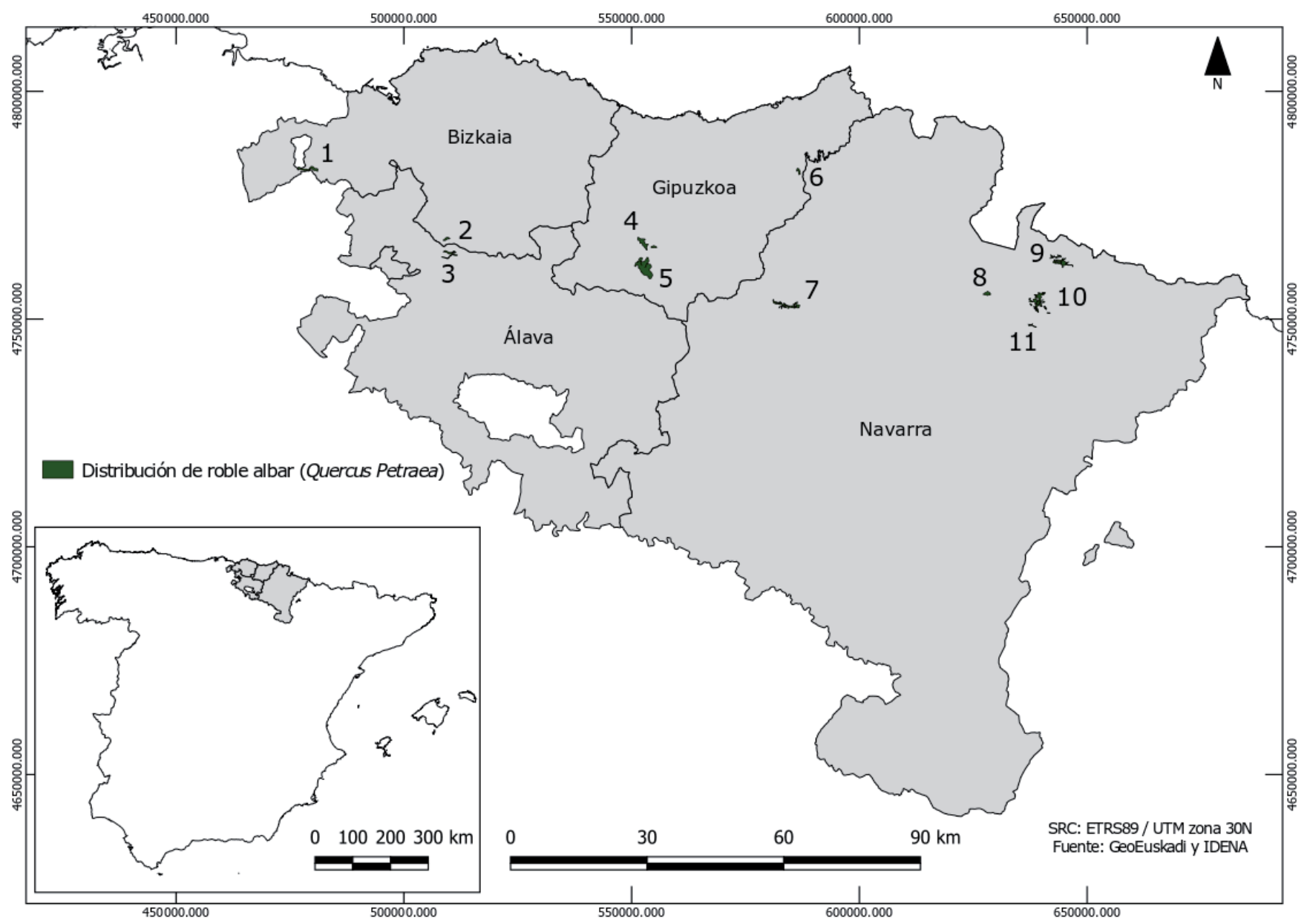

Mapa 1. Localización de las manchas de robledal de Quercus petraea en el País Vasco y Navarra. Fuente: Elaboración propia a partir de GeoEuskadi e IDENA.

El tema de la progresión del haya en el ámbito de estudio presenta alto grado de interés, puesto que es posible que, en la medida en la que se iba expandiendo, entrara en franca competencia con el roble albar y otros Quercus -caducifolios y perennifolios- que, según Carrión et al. (2000), se encontraban en estas mismas localizaciones del norte peninsular en el interglaciar previo a la última glaciación Wurmiense, en el Pleistoceno superior. Durante todo el Wurniense, especialmente en sus últimas fases, que según autores como Bradley (1999) fueron especialmente frías, géneros como Pinus, Betula, Abies, Juniperus, Quercus, Ulmus, Alnus, Corylus, Fraxinus, Pistacia, Olea, Myrtus, Ilex, etc. se refugiarían en las zonas costeras y en los valles intramontanos. Hay que recordar que el territorio de estudio, a caballo entre los Pirineos y la cordillera cantábrica, cuenta con elevaciones y sierras mucho más modestas y, de hecho, no se atestiguan importantes morfologías derivadas de los procesos glaciares y, por tanto, el denominado como "umbral vasco" (Lozano et al., 2020)pudo funcionar perfectamente como un refugio, en este caso no para el haya, puesto que el polen de la especie no es citado para ningún yacimiento, sino para el género Quercus y el resto de géneros citados anteriormente.

Es importante señalar también la influencia que el ser humano ha tenido con respecto a las dinámicas de las diferentes especies arbóreas. Según estudios como el de Pèlach et al. (2007 y 2011) o Gassiot et al. (2014), en los Pirineos existiría una secuencia contrastada: del 6.000 al 4.200 AP existiría una clara dominancia de los bosques de frondosas mesófilas, entre ellos los Quercus (no Fagus), y ninguna influencia humana. Del 4.300 al 3.300 AP se inicia la presencia humana atestiguada en diversos yacimientos arqueológicos; $y$, con ella, los primeros incendios y la regresión de los caducifolios en beneficio del género Pinus, fundamentalmente Pinus uncinata Ramond ex A.DC. y P. sylvestris L. También, desciende el timberline (es decir, el límite 
superior del bosque) entre los pisos, lo cual atestigua un calentamiento gradual. Entre el 3.300 y el 1.500 AP se incrementa el impacto humano, con utilización sistemática del fuego en favor de los pastos montanos y los primeros cultivos. De lo que es posible colegir que, en la medida en que la presencia humana se hizo más fuerte y su presión sobre el medio fue in crescendo, fundamentalmente por incendios y tala, el declive de los planifolios mesófilos pudo ayudar a que especies oportunistas como el haya o los pinos pudieran colonizar territorios que antes estaban ocupados por Q. petraea. A lo que habría que sumar que a esta especie también le pudo afectar, de manera no tan acusada, el progresivo calentamiento climático y el descenso del timberline.

En definitiva, la presencia del roble albar en el territorio se remonta, al menos, al Pleistoceno superior. Es al inicio del Holoceno, cuando, con la atemperación del frío cuaternario, fue colonizando el terreno anteriormente ocupado por formaciones de tipo tundra y taiga. Pero su pujanza empezaría a declinar cuando, quizá debilitado por haber sufrido la crisis climática del periodo Boreal (Loidi, 1983; Streiff, 1998; Pèlach et al. 2016), en el Subatlántico empezó a expandirse su duro competidor F. sylvatica, especie que, desde entonces, no ha hecho sino desalojarlo de las cotas más elevadas de su jurisdicción potencial. Esta regresión del roble albar y la proliferación del haya es coincidente con la intensificación del fuego y la tala por parte de las comunidades humanas englobadas dentro del Neolítico. Se puede afirmar, entonces, que Q. petraea, actualmente en regresión frente a la más competitiva $F$. sylvatica, es una reliquia de los bosques ancestrales de frondosas (Gobierno Vasco, 1991). Ahora bien, si los suelos en los que medra son muy pedregosos y raquíticos, el roble albar puede competir ventajosamente con el haya, incluso superarla en altitud, produciéndose una llamativa inversión de pisos de vegetación. Es también remarcable el que, en el ámbito pirenaico, Q. petraea se sitúe en la encrucijada de tres bio-regiones europeas (Alpina, Atlántica y Mediterránea), hecho excepcional que le confiere un papel biogeográfico de primera magnitud.

En definitiva, existen pocas investigaciones y estudios de caracterización centrados en esta formación y para el ámbito territorial que nos ocupa. Además, es muy posible, por la bibliografía antes reseñada, que estas formaciones puedan ser consideradas como verdaderas relictas $y$, además, muestren dinámicas regresivas, en desventaja frente a otras especies como el haya que las siguen desplazando. Es necesario, por tanto, no sólo caracterizar sistemáticamente cada una de las manchas, sino compararlas y determinar, a partir de su evaluación biogeográfica, su diagnóstico valorativo de cara a poner en valor, proteger y gestionar adecuadamente unas masas arbóreas cada vez más escasas y, por tanto, en peligro de desaparición.

\section{METODOLOGÍA}

A partir de la información de los visores cartográficos de GeoEuskadi e Idena (para Navarra), hemos seleccionado todas las manchas de bosques de Q. petraea. Los núcleos potenciales son los 11 referenciados en el mapa 1. Para el presente trabajo se ha constatado que la mancha $n^{\circ} 3$, localizada en el sector alavés del Parque Natural de Gorbea, no es estrictamente un bosque de roble albar, sino que el taxón aparece de forma diseminada sin configurar verdaderos bosques y formando parte minoritaria del dominante hayedo con ejemplares híbridos de Q.s pyrenaica Willd. x Q. petraea, lo que nos ha aconsejado desestimarla. En su defecto tomamos en cuenta la mancha $n^{\circ} 2$ del sur de Vizcaya, inserta también en el Parque Natural del Gorbea y de extensión muy reducida. En el caso de Guipúzcoa, nos decantamos por la mancha n 5 (Pikandi-Barrendiola) por ser la más extensa y ubicarse dentro del Parque Natural del Aizkorri. También se prospectó la $n^{\circ}$ 6, en el término municipal de Hernani (Guipúzcoa), en el nororiente de esta provincia, sobre la que pesaban importantes dudas ya que el trabajo de campo y reconocimiento ha podido constatar que, en este caso, los ejemplares de $Q$. petraea son muy pocos en comparación con el dominante $Q$. robur. En definitiva, en este caso, al igual que ocurría en el Gorbea, sólo existen ejemplares aislados de robles albares que no forman verdaderas masas forestales y que también se hibridan con su congénere carballo. La tercera mancha estudiada ( $\left.n^{\circ} 10\right)$, una de las más extensas y representativas del territorio navarro, es la de Garralda, sita muy cerca de la frontera con Francia. También se estudió la mancha más occidental ( $\left.n^{\circ} 1\right)$, ubicada en Las Encartaciones Vizcaínas limítrofes con tierras burgalesas; pero, a día de hoy, no contamos con el número de 
inventarios suficientes como para poder sacar conclusiones y realizar las necesarias comparaciones con los otros tres núcleos.

Una vez prospectadas todas las manchas de Q. petraea citadas en diferentes obras (Gobierno Vasco, 1991; Rivas, 1991; Aramburu, 1996; Blanco el al., 1997; Aizpurua et al., 1999) y predefinidas las unidades y su ubicación, se levantó un total de 10 inventarios para cada una las tres zonas de estudio, con visitas en estaciones diferentes (primavera, verano y otoño) para evitar los posibles sesgos fenológicos.

El modelo de inventario ha sido ensayado, contrastado y corregido en sucesivas ocasiones (Lozano et al., 2020), de cara a recoger todos los datos geográficos, medioambientales, patrimoniales y biogeográficos necesarios para la posterior valoración. En primer lugar y, para cada uno de los inventarios, se obtuvieron los datos de localización e identificación del lugar (coordenadas UTM, topónimos, etc.), aspectos y rasgos geográficos y medioambientales generales (climáticos, topográficos, litológicos, geomorfológicos, edáficos e hidrológicos), fotografías de la parcela, etc. A continuación, se tomaron los datos sobre todos los taxones de la flora vascular, así como de la fúngica y liquénica, y de las especies de la briofita (estrato muscinal).

Para determinar las coberturas se ha seguido un método de valoración clásico (Método sigmatista de la escuela de Braum-Blanquet), con una escala de 6 clases (+= menos del 1\%, 1 entre el $1 \%$ y el 10\%, 2 entre el $10 \%$ y el $25 \%$, 3 entre el $25 \%$ y el $50 \%$, 4 entre el $50 \%$ y el $75 \%$ y 5 entre el $75 \%$ y el $100 \%$ ) por cada uno de los estratos y el global de la agrupación vegetal. En aras a una mayor precisión, los datos de cobertura, de naturaleza cualitativa, se han pasado a porcentajes utilizando la media de cada una de esas horquillas (por ejemplo, para la clase + el valor medio es 0,5\%, para el 1 su valor medio sería 5\%, así sucesivamente) y así para cada especie y en cada inventario. Posteriormente se suman los valores y se dividen por el número de inventarios donde aparecía el taxón, de manera que se obtiene el porcentaje global de la especie (Tabla 1).

Para el análisis de las diferentes variables se han tomado en cuenta los resultados obtenidos de los taxones identificados, número global de especies y por grandes grupos fisiográficos, así como de su cobertura. Para el de la estructura de cada una de las formaciones se han tenido en cuenta las medias de las diferentes coberturas por estratos de vegetación (más de $5 \mathrm{~m}$; entre 1 y $5 \mathrm{~m}$; entre 0,5 y $1 \mathrm{~m}$ y por debajo de 0,5 m) para cada uno de los inventarios y, con ello, se han obtenido las coberturas medias de los tres sininventarios. La obtención de datos sobre la distribución corológica y el estatus de las plantas integrantes de los cortejos de las tres formaciones de estudio se ha abordado consultando el trabajo de Aizpurua et al. (1999) para, posteriormente, elaborar los correspondientes gráficos.

En lo que respecta a la metodología LANBIOEVA, hay que señalar que descansa en dos conceptos valorativos fundamentales: el Interés de Conservación y la Prioridad de Conservación. El Interés de Conservación resulta del sumatorio de las calificaciones obtenidas por el Interés Natural y el Interés Cultural. El Interés Natural está compuesto por cuatro grupos de criterios: fitocenótico, territorial, mesológico y estructural. El interés fitocenótico engloba caracteres intrínsecos de la vegetación y del paisaje tales como la diversidad, la naturalidad, la madurez y regenerabilidad espontánea o resiliencia. El interés territorial considera los atributos de rareza, endemicidad, relictismo y carácter finícola. El interés mesológico evalúa las funciones geomorfológica, climática, hidrológica, edáfica y faunística a una escala local. El interés estructural valora la riqueza por estrato, la cobertura por estrato, la riqueza de microhábitats y la conectividad y extensión de la mancha vegetal. El Interés Cultural se calcula teniendo en cuenta dos grupos de valores. El primero de ellos es el interés patrimonial, que evalúa tres subcriterios: valor etnobotánico, valor percepcional y valor didáctico. El segundo es el interés cultural estructural, que tiene en cuenta el valor fisionómico estructural y el valor cultural estructural.

La Prioridad de Conservación se obtiene de multiplicar el Interés de Conservación por el Factor de Amenaza que pesa sobre la unidad de vegetación concernida. Ésta se calibra en función de tres parámetros: presión demográfica, accesibilidad-transitabilidad y amenazas alternativas. El coeficiente de presión demográfica prima o penaliza situaciones de alta o baja densidad de población, con mayor o menor peligro, respectivamente, de alteración de la vegetación. El coeficiente de accesibilidad-transitabilidad valora la mayor o menor facilidad para llegar al enclave objeto de estudio, y el "rozamiento" que éste muestra al tránsito del 
ser humano. El coeficiente de amenazas alternativas calibra otro tipo de riesgos y peligros a los que puede estar sometida la integridad de la agrupación vegetal concernida.

Para una información más detallada de cada uno de los ítems valorativos y su correspondiente escala de puntuaciones nos remitimos a Lozano et al. (2020).

\section{RESULTADOS}

\subsection{Caracterización y análisis de la diversidad específica}

En la Tabla 1 se puede visualizar la totalidad de los taxones presentes en las tres localizaciones de estudio, así como las coberturas de los sininventarios obtenidos a partir de los 30 inventarios realizados (10 por ubicación). Para una mayor precisión, las coberturas se expresan en \% (Tabla 1).

Tal y como puede observarse en la tabla 1, el robledal de Pikandi contiene 18 árboles y arbustos, 10 matas (arbustos bajos leñosos) y trepadoras y 32 hierbas (un total de 60 especies); Garralda presenta 22 árboles y arbustos, 8 matas y trepadoras y 47 hierbas (77 especies); Garrastatxu es la localidad más pobre con diferencia, acogiendo 8 árboles y arbustos, 8 matas y trepadoras y 10 herbáceas (26 especies). Llama, sin duda, la atención la disparidad en la cantidad de especies presentes en las tres localizaciones, que fluctúa entre las 77 de Garralda y las 26 de Garrastatxu. Y es que en este último enclave la masa de robledal, relativamente joven, se encuentra sobre sustratos silíceos $(\mathrm{pH} 5,4)$, con pendientes superiores al $65 \%$, con suelos realmente magros -en algunos sectores verdaderos litosoles- y sometida a una influencia antrópica notable hasta que en 1994 se integró en el Parque Natural del Gorbea.

En el caso de Garralda, las condiciones mesológicas son bastante más propicias, con sustratos silíceos, pero también calcáreos, $p H$ entre 6 y 7 , suelos algo más profundos, pendientes de moderadas a altas y una intervención antrópica no tan intensa como las atestiguadas para Garrastatxu o Pikandi. En efecto, en esta última localización el robledal albar, protegido desde 1994 (Parque Natural de Aizkorri-Aratz), ha sido sometido a una presión secular bastante intensa. En sus inmediaciones se situaban importantes explotaciones mineras y ferronas que han explotado estos bosques desde hace siglos. Por otra parte, las pendientes son, en general, bastante elevadas (por encima del 50\%), el sustrato silíceo, los suelos más bien magros, sin llegar a litosoles, y el $\mathrm{pH}$ bajo (entre 5 y 5,5 ).

Dado que resulta interesante determinar los taxones característicos de la formación de robledal albar, en general, en la tabla 2 se explicitan aquellos que se repiten en los tres lugares de estudio.

Como se puede observar en ésta, tan solo 13 de las 114 especies registradas (el 11,4\% del total) son comunes a los 3 sininventarios; algunas de ellas son, hasta cierto punto, ubiquistas, al menos en lo que respecta a matas, trepadoras y herbáceas, puesto que aparecen en esta formación, pero también en otras como los robledales de $Q$. robur, determinados hayedos e, incluso, repoblaciones con exóticas ( $Q$. rubra).

Pikandi y Garralda comparten, además de las citadas, otras 15 especies, lo que hace un total de 28 $(24,6 \%)$. Pikandi y Garrastatxu tienen en común 9 taxones que, sumados a los otros 13, harían un total de 22 (19,3\%). Garralda y Garrastatxu, los enclaves más alejados entre sí, tan solo comparten las 13 especies comunes a las tres localidades. Pikandi contaría con un $40 \%$ de originalidad (taxones que sólo aparecen en esta ubicación), Garralda un 64,9\% y Garrastatxu un 15,4\%. Pikandi y Garralda son las que más similitudes presentan en sus sininventarios, seguidas de Pikandi y Garrastatxu y, en mucha menor medida, Garrastatxu y Garralda. 
Tabla 1. Sininventarios y cobertura de especies.

\begin{tabular}{|c|c|c|c|c|}
\hline & TAXONES \Según estratos en metros & Pikandi (\%) & Garralda (\%) & Garrastatxu (\%) \\
\hline & Quercus petraea & 67,5 & 70 & 66,79 \\
\hline & Fagus sylvatica & 21,15 & 22,5 & 0,07 \\
\hline & Ilex aquifolium & 10,6 & 0,3 & - \\
\hline & Corylus avellana & 8,4 & 8,95 & - \\
\hline & Sorbus aucuparia & 2,7 & 0,7 & - \\
\hline & Frangula alnus subsp. alnus & 2,15 & 0,2 & - \\
\hline & Castanea sativa & 0,1 & 9,6 & - \\
\hline & Quercus robur & 0,2 & - & - \\
\hline & Quercus petraea x robur & 1,35 & - & - \\
\hline & Sorbus aria & 0,8 & 0,25 & 0,50 \\
\hline & Alnus glutionosa & 0,5 & - & - \\
\hline & Sorbus torminalis & 0,05 & - & - \\
\hline & Betula pendula & 0,1 & 0,05 & - \\
\hline & Crataegus monogyna & 0,15 & 2,3 & - \\
\hline$\stackrel{5}{\curvearrowright}$ & Prunus avium & 0,05 & 0,75 & - \\
\hline$\frac{\widetilde{w}}{<}$ & Taxus baccata & 0,5 & - & - \\
\hline 出 & Larix decidua & 0,05 & - & - \\
\hline $\begin{array}{l}\text { O } \\
\stackrel{0}{x}\end{array}$ & Erica arborea subsp. arborea & 0,5 & - & 6,64 \\
\hline & Buxus senpervirens & - & 22 & - \\
\hline & Pyrus cordata & - & 0,05 & - \\
\hline & Fraxinus excelsior & - & 2,3 & - \\
\hline & Acer campestre & - & 2,35 & - \\
\hline & Tilia platyphyllos & - & 0,1 & - \\
\hline & Juniperus communis subsp. communis & - & 0,05 & - \\
\hline & Populus tremula & - & 0,1 & - \\
\hline & Prunus spinosa & - & 0,6 & - \\
\hline & Ulmus glabra & - & 0,5 & - \\
\hline & Quercus pubescens & - & 0,05 & - \\
\hline & Quercus x calvescens & - & 0,05 & - \\
\hline & Quercus pyrenaica & - & - & 3,29 \\
\hline & Quercus $x$ trabuti & - & - & 6,86 \\
\hline & Arbutus unedo & - & - & 10,36 \\
\hline & Sorbus torminalis & - & - & 0,14 \\
\hline
\end{tabular}




\begin{tabular}{|c|c|c|c|c|}
\hline \multirow{15}{*}{ 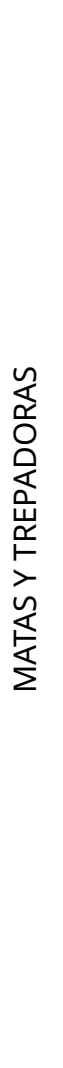 } & TAXONES \Según estratos en metros & Pikandi (\%) & Garralda (\%) & Garrastatxu (\%) \\
\hline & Vaccinium myrtillus & 27,55 & 5,3 & 25,43 \\
\hline & $\begin{array}{l}\text { Lonicera periclymenum subsp. periclyme- } \\
\text { num }\end{array}$ & 4,1 & 44 & 1,50 \\
\hline & Rubus ulmifolius & 2,3 & 12,05 & 3,07 \\
\hline & Hedera helix & 4,45 & 26,5 & 3,71 \\
\hline & Calluna vulgaris & 1,95 & - & 2,86 \\
\hline & Erica vagans & 2,95 & - & 0,36 \\
\hline & Ruscus aculeatus & 3,75 & - & 0,07 \\
\hline & Daphne laureola subsp. laureola & 0,2 & - & - \\
\hline & Hypericum androsaemum & 0,15 & - & - \\
\hline & Daboecia cantabrica & 1,75 & - & 2,29 \\
\hline & Tamus communis & - & 17,55 & - \\
\hline & Cytisus scoparius subsp. cantabricus & - & 0,1 & - \\
\hline & Clematis vitalba & - & 3,8 & - \\
\hline & Rosa canina subsp. squarrosa & - & 17,6 & - \\
\hline \multirow{19}{*}{ 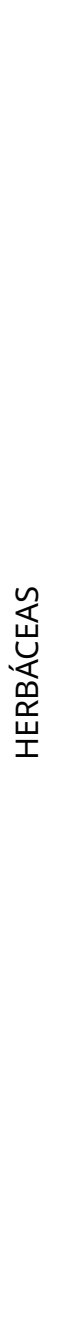 } & Pteridium aquilinum & 8,05 & 17,75 & 13,21 \\
\hline & Blechnum spicant & 8,9 & - & 1,50 \\
\hline & Oreopteris limbosperma & 2,45 & 0,05 & 0,07 \\
\hline & Polistichum setiferim & 0,05 & - & - \\
\hline & Deschampsia flexuosa & 2,3 & 47,4 & 5,93 \\
\hline & Serratula tinctorea subsp. seoanei & 0,05 & - & - \\
\hline & Erythronium dens-canis & 0,25 & - & - \\
\hline & Anemone nemorosa & 0,65 & 14,4 & - \\
\hline & Euphorbia dulcis & 0,9 & 0,1 & 0,93 \\
\hline & Polygala serpyllifolia & 0,05 & - & - \\
\hline & Oxalis acetosella & 0,8 & - & 0,29 \\
\hline & Agrostis curtisii & 0,85 & - & 5,07 \\
\hline & Solidago virgaurea & 1,65 & 0,1 & - \\
\hline & Teucrium scorodonia & 0,05 & 26,45 & 1,57 \\
\hline & Melampyrum pratense & 0,55 & - & - \\
\hline & Polygonatum odoratum & 0,15 & 0,05 & - \\
\hline & Saxifraga hirsuta subsp. hirsuta & 0,5 & - & - \\
\hline & $\begin{array}{l}\text { Euphorbia amygdaloides subsp. amygda- } \\
\text { loides }\end{array}$ & 0,6 & 8,9 & - \\
\hline & Ranunculus tuberosus & 1,05 & - & - \\
\hline
\end{tabular}




\begin{tabular}{|c|c|c|c|c|}
\hline & TAXONES \Según estratos en metros & Pikandi (\%) & Garralda (\%) & Garrastatxu (\%) \\
\hline & Lysimachia nemorum & 0,15 & - & - \\
\hline & Cardamine hirsuta & 0,05 & - & - \\
\hline & Viola riviniana & 0,6 & 8,85 & - \\
\hline & Brachypodium sylvaticum subsp. sylvaticum & 1,1 & 9,55 & 6,79 \\
\hline & Luzula sylvatica subsp. henriquesii & 0,05 & - & - \\
\hline & Lathraea clandestina & 0,05 & - & - \\
\hline & Stachys officinalis subsp. officinalis & 0,55 & 0,1 & - \\
\hline & Ajuga reptans & 0,1 & - & - \\
\hline & Potentilla erecta & 0,05 & - & 2,64 \\
\hline & Carex sp. & 0,1 & - & - \\
\hline & Aquilegia vulgaris subsp. vulgaris & 0,05 & - & - \\
\hline & Phyteuma pyrenaicum & 0,05 & - & - \\
\hline & Circaea lutetiana subsp. Iutetiana & 0,05 & - & - \\
\hline & Symphytum tuberosum & - & 0,05 & - \\
\hline & Asphodelus albus & - & 14,45 & - \\
\hline & Silene latifolia subsp. alba & - & 0,15 & - \\
\hline 岂 & Stellaria media & - & 17,6 & - \\
\hline 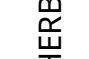 & Polypodium interjectum & - & 17,7 & - \\
\hline & Lamium galeobdolon subsp. montanum & - & 8,8 & - \\
\hline & Melica uniflora & - & 8,85 & - \\
\hline & Veronica chamaedrys & - & 17,6 & - \\
\hline & Senecio sp. & - & 8,8 & - \\
\hline & Melanpirum pratense & - & 8,75 & - \\
\hline & Arenaria grandiflora subsp. grandiflora & - & 0,05 & - \\
\hline & Pulmonaria longifolia & - & 0,1 & - \\
\hline & Fragaria vesca & - & 8,8 & - \\
\hline & Laserpitium prutenicum subsp. dufourianum & - & 8,85 & - \\
\hline & Cephalanthera damasonium & - & 0,05 & - \\
\hline & Picris hieracoides & - & 0,05 & - \\
\hline & Orchis purpura & - & 0,05 & - \\
\hline & Geranium robertianum & - & 1,85 & - \\
\hline & Oroblanchaceae & - & 0,05 & - \\
\hline & Holcus lanatus & - & 0,05 & - \\
\hline & Lathyrus linifolius & - & 0,05 & - \\
\hline & Crepis capillaris & - & 0,05 & - \\
\hline
\end{tabular}




\begin{tabular}{|c|c|c|c|c|}
\hline \multirow{14}{*}{ 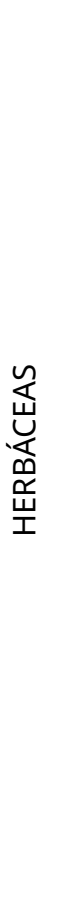 } & TAXONES \Según estratos en metros & Pikandi (\%) & Garralda (\%) & Garrastatxu (\%) \\
\hline & Geum urbanum & - & 3,5 & - \\
\hline & Hepatica nobilis & - & 1,8 & - \\
\hline & Arum italicum & - & 0,1 & - \\
\hline & Vicia sativa subsp. cordata & - & 17,5 & - \\
\hline & Iris graminea & - & 8,8 & - \\
\hline & Helleborus viridis & - & 0,05 & - \\
\hline & Primula acaulis & - & 17,5 & - \\
\hline & Ranunculus nemorosus & - & 8,8 & - \\
\hline & Dactylis glomerata & - & 17,5 & - \\
\hline & Vicia cracca & - & 0,05 & - \\
\hline & Taraxacum officinale & - & 8,75 & - \\
\hline & Scrofularia canina subsp. canina & - & 0,05 & - \\
\hline & Asplenium trichomanes & - & 0,05 & - \\
\hline \multirow{7}{*}{ 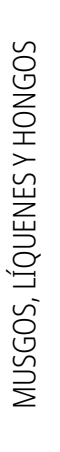 } & Líquenes ligados troncos y ramas & 33,5 & 35,5 & 34,07 \\
\hline & Líquenes ligados a suelo y rocas & 42,1 & 12,5 & 56,07 \\
\hline & Musgos en troncos & 38,7 & 23,5 & 27,50 \\
\hline & Musgos en rocas y suelos & 36,8 & 32 & 33,21 \\
\hline & Hongos & 26,45 & 0 & 0,29 \\
\hline & Hojarasca & 65 & 41,5 & 42,50 \\
\hline & Suelo o roca desnuda & 70,1 & 13,25 & 25,93 \\
\hline
\end{tabular}

Fuente: Elaboración propia.

Tabla 2. Especies compartidas por las tres ubicaciones y sus porcentajes de cobertura.

\begin{tabular}{|c|c|c|c|}
\hline & Pikandi & Garralda & Garrastatxu \\
\hline Quercus petraea & 67,5 & 70 & 66,79 \\
\hline Fagus sylvatica & 21,15 & 22,5 & 0,07 \\
\hline Sorbus aria & 0,8 & 0,25 & 0,5 \\
\hline Vaccinium myrtillus & 27,55 & 5,3 & 25,43 \\
\hline $\begin{array}{l}\text { Lonicera periclymenum } \\
\text { subsp. periclymenum }\end{array}$ & 4,1 & 44 & 1,5 \\
\hline Rubus ulmifolius & 2,3 & 12,05 & 3,07 \\
\hline Hedera helix & 4,45 & 26,5 & 3,71 \\
\hline Pteridium aquilinum & 8,05 & 17,75 & 13,21 \\
\hline Oreopteris limbosperma & 2,45 & 0,05 & 0,07 \\
\hline Deschampsia flexuosa & 2,3 & 47,4 & 5,93 \\
\hline
\end{tabular}




\begin{tabular}{|l|c|c|c|}
\cline { 2 - 4 } \multicolumn{1}{c|}{} & Pikandi & Garralda & Garrastatxu \\
\hline Euphorbia dulcis & 0,9 & 0,1 & 0,93 \\
\hline Teucrium scorodonia & 0,05 & 26,45 & 1,57 \\
\hline $\begin{array}{l}\text { Brachypodium sylvaticum } \\
\text { subsp. sylvaticum }\end{array}$ & 1,1 & 9,55 & 6,79 \\
\hline
\end{tabular}

Fuente: Elaboración propia.

\subsection{Análisis de la estructura}

La tabla 3 muestra bien a las claras la alta cobertura del dosel arbóreo de roble albar (entre el 78,8\% en Pikandi y el 62,6\% en Garrastatxu), prácticamente monoespecífico; lo que contrasta con la riqueza florística del sotobosque, que tanto difiere de la indigencia del contiguo hayedo, especialmente en el caso de Pikandi. Los estratos intermedios presentan coberturas modestas que llegan, como mucho, al tercio; mientras que en el de entre 0,5 y $1 \mathrm{~m}$ es aún más reducida. El estrato de menos de 0,5 m, normalmente el ocupado por las herbáceas, presenta alta cobertura en Pikandi (más del 50\%), menor en Garrastatxu (40\%) y de un tercio en Garralda.

Tabla 3. Porcentajes de cobertura por ubicación y estrato.

\begin{tabular}{|l|c|c|c|}
\hline \multicolumn{1}{|c|}{ Estratos } & Pikandi (\%) & Garralda (\%) & Garrastatxu (\%) \\
\hline Más de 5 metros & 78,8 & 72,5 & 62,6 \\
\hline entre 1 y 5 metros & 39,8 & 34,8 & 35,8 \\
\hline entre 0,5 y 1 metro & 27,6 & 24,6 & 26,8 \\
\hline menos de 0,5 m & 54,3 & 32,5 & 40,0 \\
\hline
\end{tabular}

Fuente: Elaboración propia.

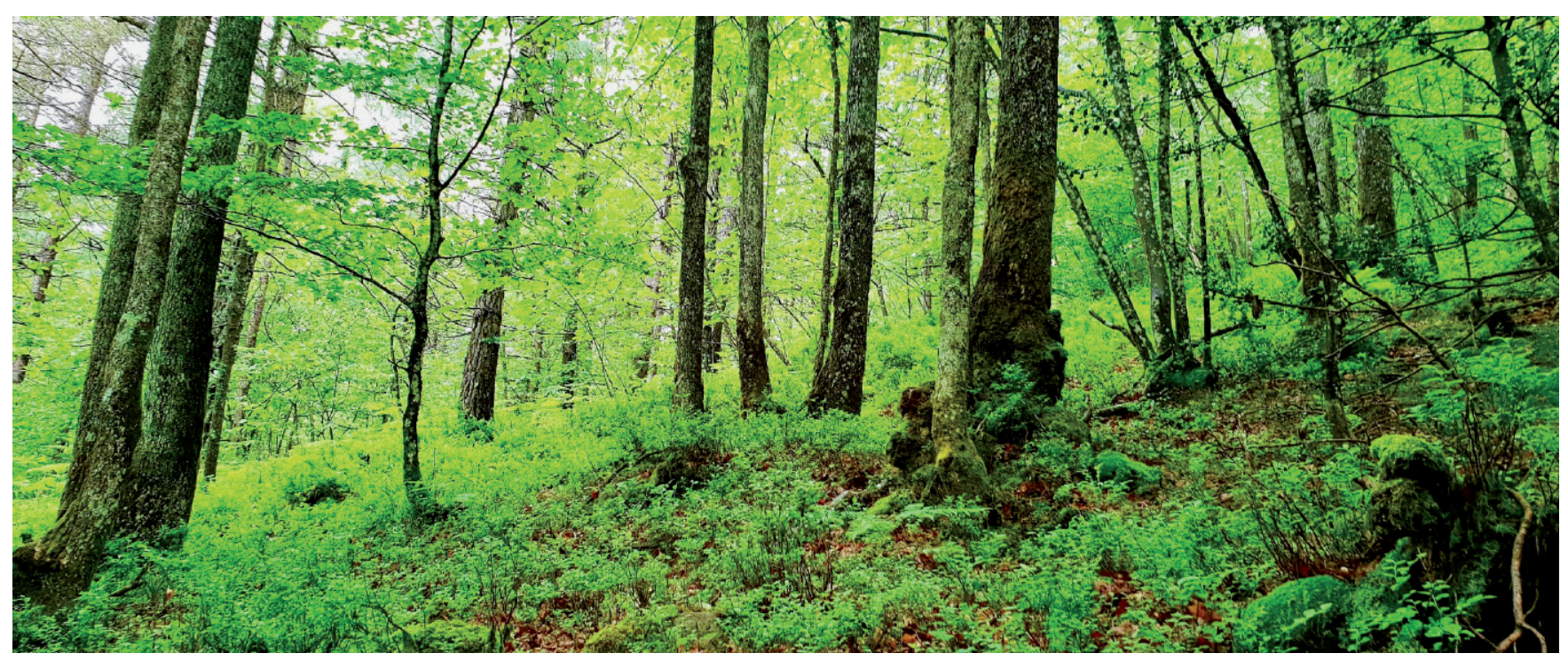

Fotografía 1. Robledal de Quercus petraea de Pikandi. Obsérvese la gran cobertura tanto arbórea como del estrato inferior. Fuente: Autores. 


\subsection{Análisis de la filiación corológica}

Los gráficos 1, 2 y 3 reflejan la filiación corológica de los taxones inventariados en las tres ubicaciones de estudio.
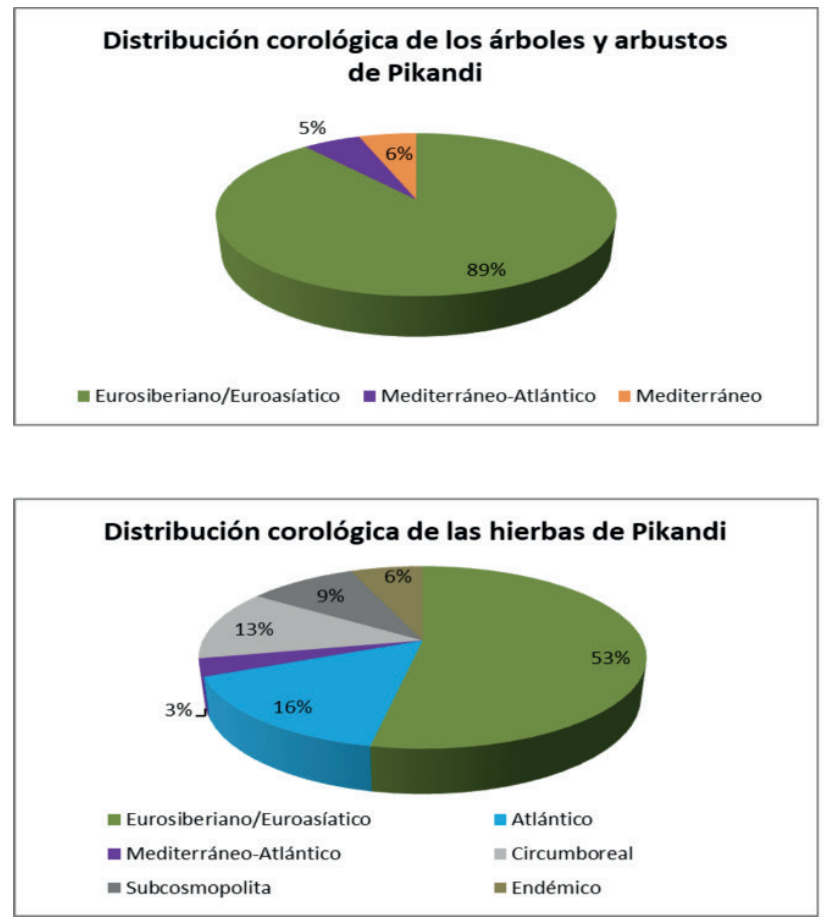
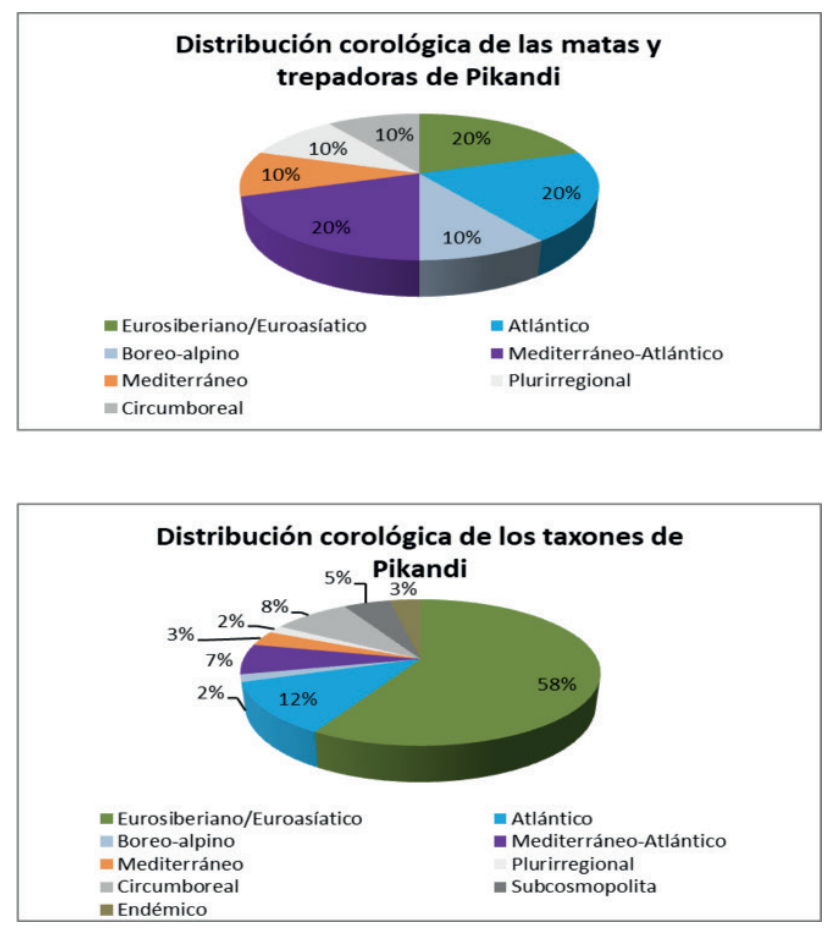

Gráfico 1. Filiación corológica de los taxones de Pikandi. Fuente: Elaboración propia.

En el conjunto de Pikandi domina la filiación eurosiberiana/euroasiática (58\%), seguida de la atlántica (12\%), de lo que resulta un $70 \%$ de taxones con claro carácter eurosiberiano. En un segundo plano se situarían los circumboreales, subcosmopolitas y plurirregionales ( $8 \%, 5 \%$ y $2 \%$ respectivamente), los de la transición entre lo atlántico y lo mediterráneo (7\%), los mediterráneos y los endémicos (con sendos 3\%) y los orófitos boreo-alpinos (2\%).

En cuanto a las filiaciones por grandes grupos, el de herbáceas ofrecería similares proporciones, cabiendo destacar el notable número de taxones endémicos, ausentes en el resto de los grupos. En matas y trepadoras el reparto es más diverso: dominan las eurosiberianas, atlánticas y de transición mediterráneo-atlántica, todas ellas con un 20\%; en tanto que los taxones boreo-alpinos, circumboreales y plurirregionales suponen un $10 \%$ cada uno. En el grupo de los árboles, el dominio de los taxones eurosiberianos-euroasiáticos es abrumador (89\%), pues los mediterráneos solo suponen el 6\% y los de transición mediterráneo-atlántica el $5 \%$. Si tenemos en cuenta que los árboles cuentan con una gran cobertura y dentro de ellos dominan las filiaciones eurosiberianas, se puede afirmar que este bosque muestra una filiación mayoritariamente eurosiberiana-atlántica y, por tanto, responde, no sólo a la ubicación geográfica propia, sino a unas características mesológicas muy típicas de las que se pueden encontrar dentro de las mencionadas filiaciones.

En el caso de Garralda, la distribución corológica general responde a filiaciones eurosiberianas/euroasiáticas (61\%), seguidas de la circumboreal (9\%), plurirregional (8\%), mediterránea (5\%), subcosmopolita (4\%), atlántica y de transición atlántico-mediterránea (4\%), orófita boreo-alpina (2\%) y, por último, endemica y orófita alpino-pirenaica (1\%).

El grupo de árboles y arbustos lo monopoliza, prácticamente, la componente eurosiberiana (91\%), por tan sólo un 9\% del mediterránea. Muy distinto es lo que sucede en el de matas y trepadoras puesto que, aunque sigue dominando la eurosiberiana/euroasiática (50\%), la endémica y la circunboreal alcanzan el $13 \%$. 

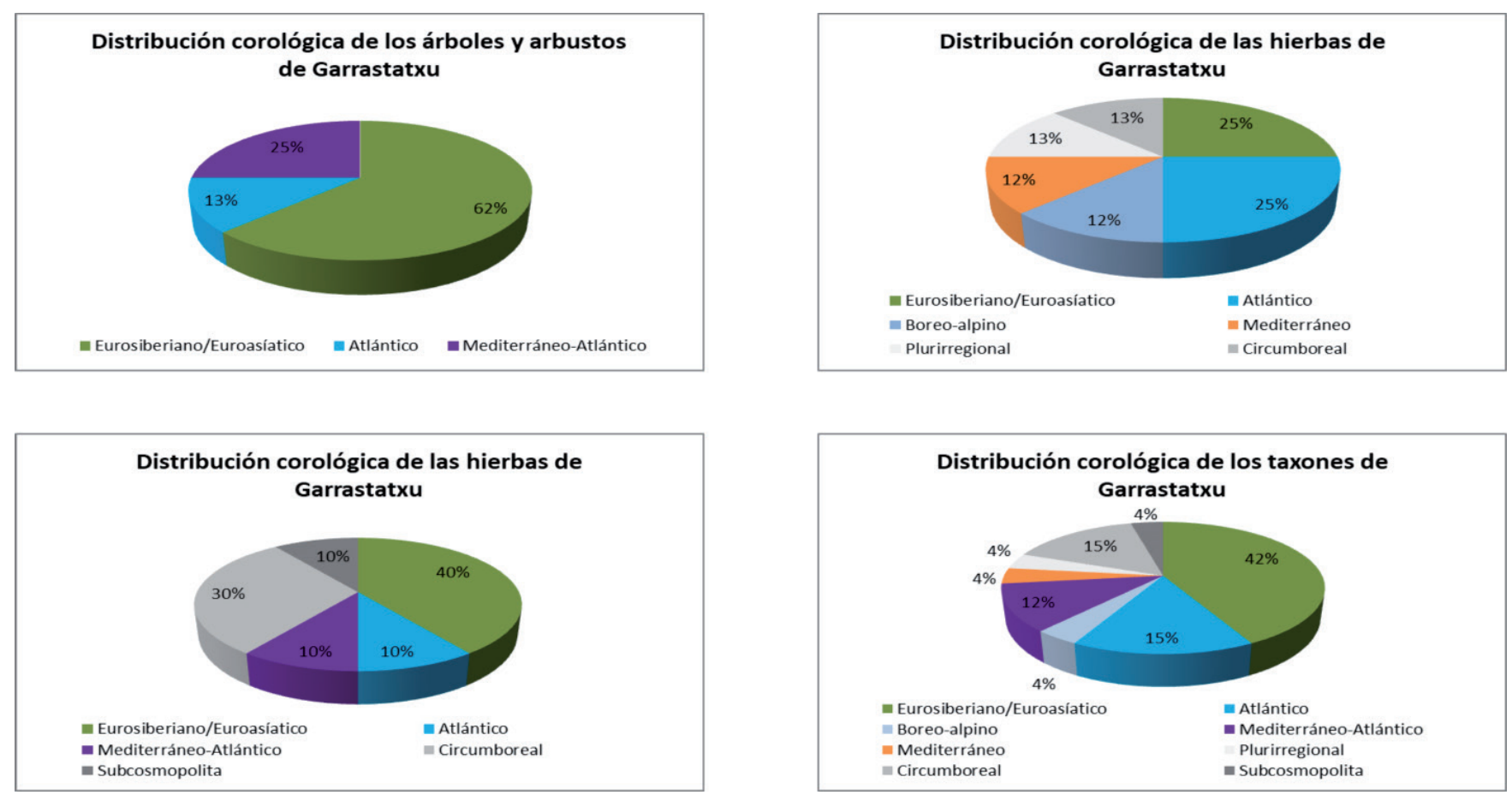

Gráfico 2. Filiación corológica de los taxones de Garralda. Fuente: Elaboración propia.

No existe ningún taxón mediterráneo, pero sí de transición mediteráneo-atlántica y boreo-alpina (12\% para ambas). En cuanto a las herbáceas, al igual que ocurría en Pikandi, la realidad es mucho más compleja: domina la componente eurosiberiana/euroasiática (49\%), seguida, a gran distancia, por la circumboral (9\%), plurirregional (8\%), mediterránea (5\%), subcosmopolita, atlántica y de transición atlántico-mediterránea (4\%) y orófita boreoalpina (2\%) y orófita mediterránea y endémica (1\%).
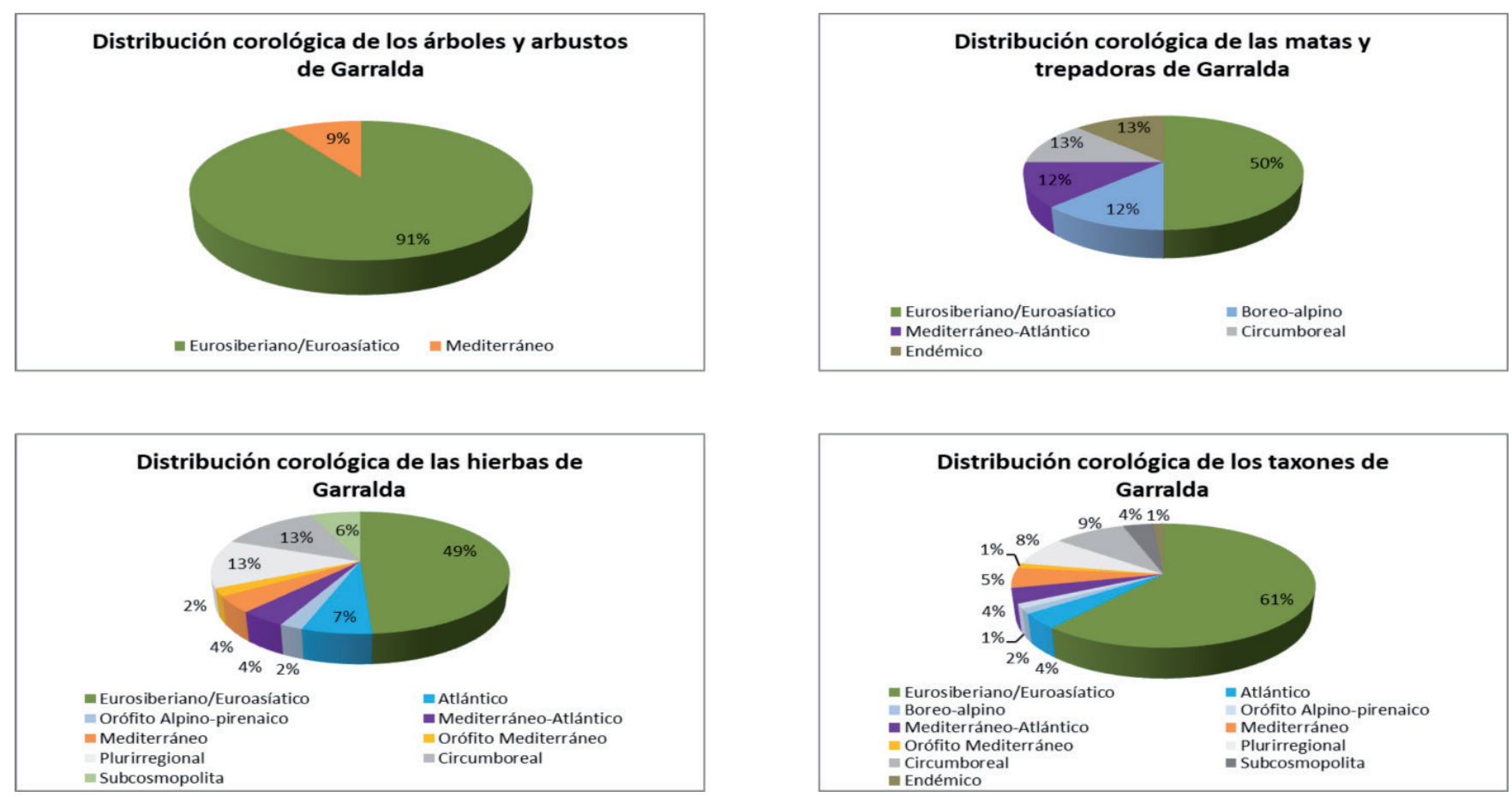

Gráfico 3. Filiación corológica de los taxones de Garrastatxu. Fuente: Elaboración propia. 
En Garrastatxu no se alcanza la complejidad de Pikandi pero, sobre todo, de Garralda. Dominan los taxones de filiación eurosiberiana (42\%), seguidos de los atlánticos y circumboreales (15\%), de transición atlántico-mediterránea (12\%) y subcosmopolitas y plurirregionales, mediterráneas y de orófitos boreo-alpinos (4\%).

En el grupo de árboles y arbustos el 62\% responde a una filiación eurosiberiana/euroasiática, seguida de la de transición atlántico-mediterránea (25\%) y atlántica (13\%). En matas y trepadoras domina la filiación eurosiberiana (40\%), seguida de la circumboreal (30\%) y atlántica, de transición atlántico-mediterránea y subcosmopolita (10\%). En hierbas, se imponen la eurosiberiana/euroasiática y la atlántica (25\%), sendos $13 \%$ se corresponden con las filiaciones circumboreal y plurirregional, y el $12 \%$ con la mediterránea y la de orófitos boreo-alpinos.

En definitiva, el robledal albar de Pikandi se configura como el más netamente atlántico o eurosiberiano, seguido por el de Garralda y, por último, el de Garrastatxu. El que más taxones mediterráneos contiene es el de Garralda, seguido por el de Garrastatxu y el de Pikandi. En cuanto a los porcentajes de especies a caballo entre lo atlántico y lo mediterráneo, domina el de Garrastatxu, seguido del de Pikandi y Garralda.

La existencia de endemismos y orófitos es un síntoma de calidad al contar con especies de una distribución territorial muy restringida. En este sentido, el robledal albar de Pikandi contiene un 3\% de endemismos (Luzula sylvatica subsp. henriquesii y Lathraea clandestina), Garralda un 1\% (Cytisus scoparius subsp. cantabricus) y Garrastatxu carece de ellos. Sin embargo, este último muestra un porcentaje del $4 \%$ en orófitos boreoalpinos (Vaccinium myrtillus), y Garralda y Pikandi un 2\% (Vaccinium myrtillus). Especial es el caso de Garralda, donde al citado $2 \%$ se le suma el $1 \%$ de orófitos pirenaico-alpinos (Asphodelus albus) y un sorprendente $1 \%$ de orófitos mediterráneos (Arenaria grandiflora subsp. grandiflora).

\subsection{Análisis del estatus de las especies}

El gráfico 4 muestra el estatus de las especies en las tres ubicaciones, es decir, su grado de rareza y, por tanto, amenaza de desaparición o peligro.

Tal y como puede observarse, sólo en el caso de Garralda existen taxones muy raros (Iris graminea). En lo que respecta a los raros, se han identificado en Garralda (Orchis purpurea y Polygonatum odoratum) y Pikandi (Taxus baccata y Polygonatum odoratum). El número de especies escasas es, para las tres ubicaciones, relativamente elevado, dándose el más alto en Garrastatxu (54\%), seguido de Pikandi (50\%) y Garralda (44\%). En lo que respecta a las especies comunes, el mayor porcentaje corresponde a Garralda (39\%), seguido de Pikandi (30\%) y Garrastatxu (23\%). En las muy comunes destaca Garrastatxu (23\%), a continuación, Pikandi (17\%) y, en último lugar, Garralda (13\%). Si sumamos, por un lado, los taxones muy raros, raros y escasos (categoría esta última en la que se encuadra el propio Q. petraea) y, por otro, los comunes y muy comunes, Garrastatxu presenta un $54 \%$ de especies englobadas en el primer grupo y un $46 \%$ en el segundo; Pikandi un $45 \%$ y un $55 \%$, respectivamente; y Garralda un $48 \%$ frente al $52 \%$. 

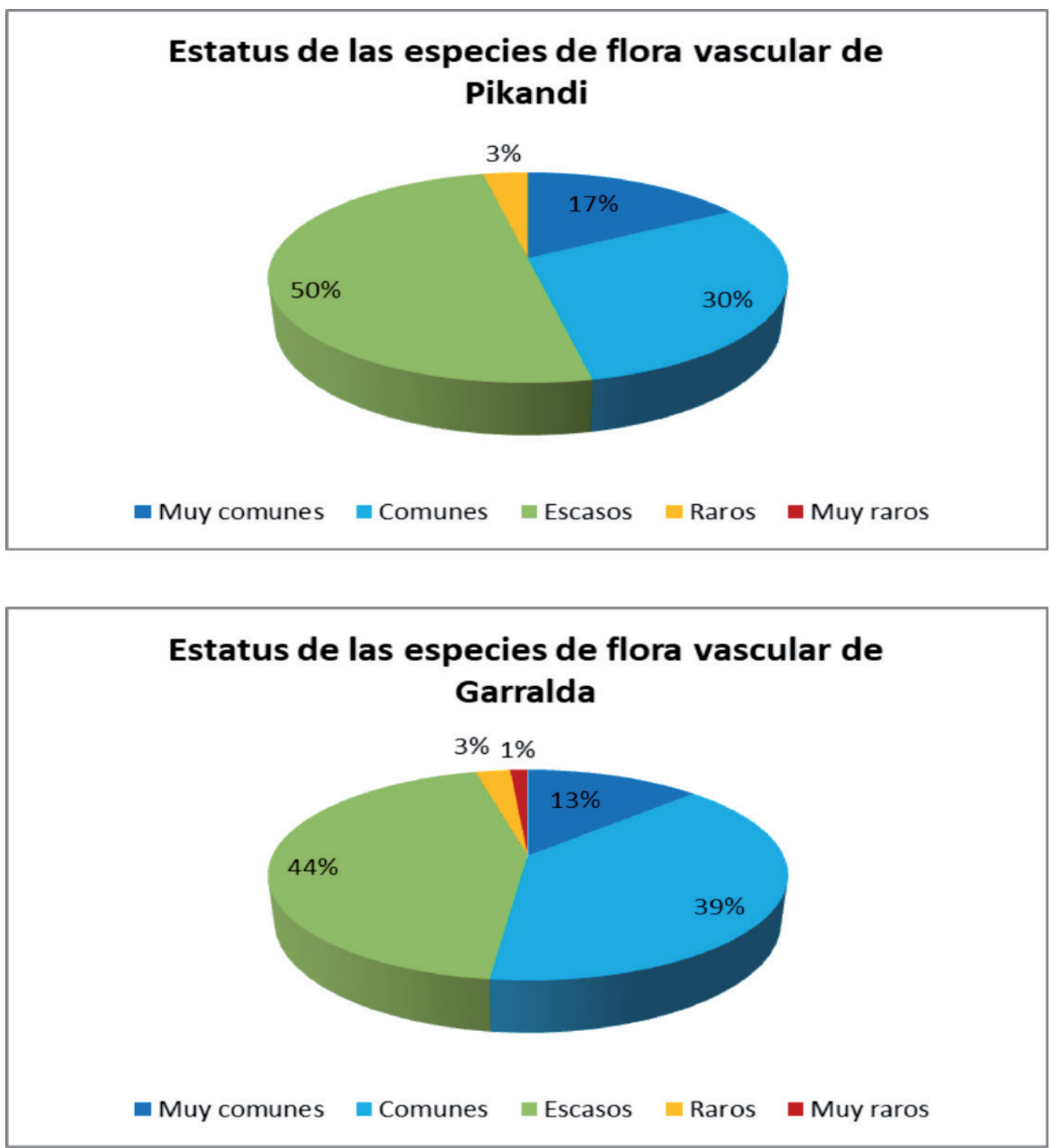

\section{Estatus de las especies de flora vascular de Garrastatxu}

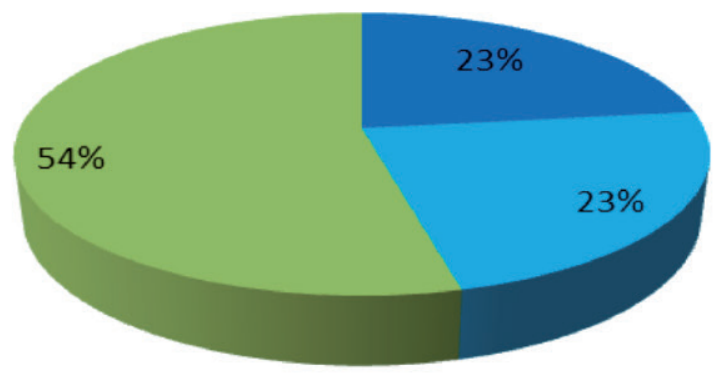

Muycomunes $\square$ Comunes Escasos $\quad$ Raros $\square$ Muy raros

Gráfico 4. Estatus de las especies vegetales en las tres ubicaciones. Fuente: Elaboración propia. 


\subsection{Valoración biogeográfica}

La tabla 4 muestra las valoraciones parciales, generales y finales resultantes de la aplicación de la Metodología LANBIOEVA.

Tabla 4. Valoración LANBIOEVA de los robledales albares de las tres ubicaciones.

\begin{tabular}{|c|c|c|c|c|c|c|c|}
\hline \multicolumn{4}{|c|}{ VALORACIÓN } & PARÁMETROS & Pikandi & Garralda & Garrastatxu \\
\hline \multirow{31}{*}{$\begin{array}{l}Z \\
\text { O } \\
Z\end{array}$} & \multirow{21}{*}{$\underset{Z}{\stackrel{5}{Z}}$} & \multirow{5}{*}{\multicolumn{2}{|c|}{ INFIT }} & DIVERSIDAD & 7,1 & 7,1 & 5,1 \\
\hline & & & & NATURALIDAD & 9,9 & 10 & 10 \\
\hline & & & & MADUREZ (x2) & 20 & 20 & 20 \\
\hline & & & & REGENERABILIDAD & 10 & 10 & 10 \\
\hline & & & & SUMA (INFIT GLOBAL) & 47 & 47,1 & 45,1 \\
\hline & & \multirow{5}{*}{\multicolumn{2}{|c|}{ INTER }} & RAREZA (x2) & 14,7 & 14,1 & 12 \\
\hline & & & & ENDEMICIDAD & 0,2 & 0 & 0 \\
\hline & & & & RELICTISMO & 6 & 5,8 & 6 \\
\hline & & & & CAR. FINÍCOLA & 0 & 0 & 0 \\
\hline & & & & SUMA (INTER GLOBAL) & 20,9 & 19,9 & 18 \\
\hline & & \multirow{6}{*}{\multicolumn{2}{|c|}{ INMES }} & F. GEOMORFOLÓGICA (x2) & 20 & 20 & 20 \\
\hline & & & & F. CLIMÁTICA & 10 & 10 & 10 \\
\hline & & & & F. HIDROLÓGICA & 10 & 10 & 10 \\
\hline & & & & F. EDÁFICA & 8 & 8 & 8 \\
\hline & & & & F. FAUNÍSTICA & 9 & 10 & 9 \\
\hline & & & & SUMA (INMES GLOBAL) & 57 & 58 & 57 \\
\hline & & \multirow{5}{*}{\multicolumn{2}{|c|}{ INEST }} & RIQ. POR ESTRATOS $(x 0,5)$ & 7,4 & 7,2 & 5,6 \\
\hline & & & & COB. POR ESTRATOS $(x 0,5)$ & 5,7 & 6,0 & 5,1 \\
\hline & & & & RIQ. DE MICROHAB. & 6,1 & 6,8 & 5,8 \\
\hline & & & & CONECT. ESPACIAL & 18 & 16,1 & 16 \\
\hline & & & & SUMA (INEST GLOBAL) & 37,2 & 36,1 & 32,5 \\
\hline & \multicolumn{4}{|c|}{ SUMA (INNAT) } & 162,1 & 161 & 152,6 \\
\hline & \multirow{7}{*}{$\underset{Z}{己}$} & \multirow{4}{*}{\multicolumn{2}{|c|}{ INPAT }} & VALOR ETNOBOTÁNICO (X2) & 15,2 & 20 & 14,6 \\
\hline & & & & VALOR PERCEPCIONAL & 9,8 & 10 & 10 \\
\hline & & & & VALOS DIDÁCTICO & 10 & 10 & 10 \\
\hline & & & & SUMA (INPAT GLOBAL) & 35 & 40 & 34,6 \\
\hline & & \multirow{3}{*}{\multicolumn{2}{|c|}{ INCULEST }} & VALOR FISIONÓMICO ESTRU & 1,5 & 2 & 2 \\
\hline & & & & VALOR CULTURAL ESTRUCT. & 2 & 5 & 2 \\
\hline & & & & SUMA (INCULEST GLOBAL) & 3,5 & 7 & 4 \\
\hline & \multicolumn{4}{|c|}{ SUMA (INCUL) } & 38,5 & 47 & 38,6 \\
\hline & \multicolumn{4}{|c|}{ SUMA (INCON) } & 200,6 & 208 & 191,2 \\
\hline \multirow{5}{*}{\multicolumn{3}{|c|}{$\begin{array}{l}\text { PRIORIDAD DE } \\
\text { CONSERVACIÓN }\end{array}$}} & & ÓN DEMOGRÁFICA & 1 & 1 & 1 \\
\hline & & & & SIBILIDAD-TRANSITABILIDAD & 5,7 & 5,2 & 3 \\
\hline & & & & IAZAS ALTERNATIVAS & 3 & 2,6 & 3 \\
\hline & & & & DR GLOBAL DE AMENAZA & 9,7 & 8,8 & 7 \\
\hline & & & & & 1946,6 & 1846,8 & 1338,5 \\
\hline
\end{tabular}

Fuente: Elaboración propia.

INFIT: Interés Fitocenótico, INTER: Interés Territorial, INMES: Interés Mesológico, INEST: Interés Estructural, INNAT: Interés Natural, INPAT: Interés Patrimonial, INCULEST: Interés Cultural Estructural, INCUL: Interés Cultural, INCON: Interés de Conservación, PRICON: Prioridad de Conservación. 
En lo referente al Interés de Conservación, en el apartado de interés natural el grupo de criterios que determinan el interés fitocenótico cuenta con puntuaciones altas, sobre todo en lo que respecta a la madurez y la regenerabilidad, esta última seriamente condicionada por el carácter relicto de la agrupación vegetal. Entre los criterios que conforman el interés territorial destacan el de rareza (a la de ciertos taxones hay que sumar la de la propia formación vegetal en el contexto regional) y, sobre todo, el de relictismo. El interés mesológico de las tres localizaciones muestra registros de altos a muy altos (siendo máximos en criterios como el geomorfológico, climático e hidrológico), comparables a los más elevados alcanzados en formaciones mediterráneas, boreales o atlánticas europeas, así como en mediterráneas americanas e incluso tropicales (Lozano et al., 2020). También los valores estructurales alcanzan puntuaciones notables, y ello pese a no tratarse de bosques especialmente intrincados y poliestratos, especialmente en el caso de Garrastatxu. En cuanto a la riqueza de microambientes, las cifras no pasan de discretas en los tres casos, lo que no se repite con la extensión y el nivel de conectividad, que son bastante aceptables, máxime al tratarse de territorios donde los bosques maduros no suelen contar con grandes superficies.

Dentro también del Interés de Conservación, en lo concerniente a los criterios de raigambre cultural, es de destacar el notable interés patrimonial del robledal albar, especialmente en su faceta etnocultural, conforme a las indagaciones hechas sobre el terreno y las entrevistas a la población local (Lozano et al., 2020). El valor percepcional, estimado a partir de encuestas a la población, alcanza en los tres casos una puntuación sobresaliente; lo mismo que el didáctico, que muestra un buen ejemplo de bosque maduro, con evidente carácter relicto, altos niveles de protección, innumerables valores eco-biotópicos y eco-biocenóticos, y un manejo secular y sostenible del bosque. Los criterios de raigambre cultural-estructural presentan registros más bien moderados en las tres localizaciones, aunque más altos en el caso de Garralda. En definitiva, el interés cultural ofrece puntuaciones de medias a altas, similares a las de otros bosques mesófilos, como los robledales de roble pedunculado o el encinar cantábrico.

Suma de los citados valores naturales y culturales, el Interés de Conservación de los robledales albares arroja puntuaciones muy elevadas, de las más altas logradas hasta la fecha para agrupaciones forestales de ámbito global (Lozano et al., 2020).

La Prioridad de Conservación resulta de multiplicar el Interés de Conservación por el nivel de amenaza. Esta última presenta valores muy contenidos en lo tocante a la densidad de población, ya que estos bosques se ubican en comarcas con baja presión demográfica. Por otra parte, la ubicación de estas florestas en lugares relativamente recónditos y con fuertes desniveles topográficos -especialmente relevantes en el caso de Garrastatxu y Pikandi- da lugar a niveles de accesibilidades muy bajas; a cambio, la transitabilidad es relativamente alta, puesto que no estamos ante bosques de estructura intrincada. Por último, el grado de amenazas alternativas es muy reducido al encontrase, en la mayoría de los casos, en zonas protegidas. De esta manera, el factor global de amenaza es muy bajo para Garrastatxu, bajo a moderado para Garralda y medio para Pikandi.

A resultas de todo ello, la Prioridad de Conservación de los robledales albares presenta altas puntuaciones en Pikandi y Garralda, siendo más discreta en Garrastatxu. En definitiva, el bajo nivel de amenaza global que muestran las tres localizaciones hace que los guarismos de urgencia proteccionista se reduzcan considerablemente. De ahí que, en el caso de los robledales albares, dirijamos nuestra atención preferente al Interés de Conservación que, como se ha referenciado anteriormente, es muy elevado, a la altura del de ciertas agrupaciones punteras del Cono Sur americano, y superior al de la generalidad de formaciones estudiadas hasta la fecha a escala global (Lozano et al., 2020).

\section{DISCUSIÓN Y CONCLUSIONES}

En la presente aportación se han estudiado y valorado tres muestras representativas de este tipo de bosque: dos en el País Vasco (Pikandi y Garrastatxu) y una en Navarra (Garralda). La escasez de esta formación (en relación al número y tamaño de sus manchas) es, si cabe, más alarmante puesto que se ha podido constatar que determinadas publicaciones (Gobierno Vasco, 1991 y Aramburu, 1996), junto a las capas cartográficas 
del Gobierno Vasco o el Gobierno de Navarra (SITNA) dan por sentado la existencia de diferentes localizaciones con este tipo de formación que, posteriormente $y$, a partir del trabajo de reconocimiento en campo, se han podido constatar cómo inexistentes puesto que la especie se encuentra con pies aislados y, en el mejor de los casos, hibridada con otras especies taxonómicamente cercanas como Q. pyrenaica o Q. robur. En este sentido, se ha cumplido con el objetivo principal enunciado. Se han prospectado todas las manchas potenciales según las distintas bases de datos, se han tomado en cuenta aquellas que realmente responden a bosques de $Q$. petraea, y se han desestimado aquellas que o bien presentan pies más o menos aislados de la especie (de manera que no llegan ni a conformar rodales) o muestran un alto grado de hibridación con las otras especies enunciadas. De esta forma, ya podemos tener una idea clara de que localizaciones como las representadas con los números 3 y 6 del mapa 1 no responden a masas de roble albar sensu stricto. Todos estos datos junto a los de las caracterizaciones de las tres ubicaciones inventariadas y estudiadas en este trabajo arrojan datos inéditos hasta la fecha que suponen un avance en los estudios biogeográficos a esta escala regional pero también a escala nacional.

También se ha abordado satisfactoriamente la necesaria comparación entre las tres manchas estudiadas, llegando a la conclusión de que son muy diferentes entre sí y que es realmente difícil realizar o completar un sininventario que realmente pueda aglutinar y representar de forma positiva a las tres.

Pese a arraigar, en todos los casos, en laderas de fuerte pendiente, sustratos petranos y suelos ácidos y oligotróficos, los robledales albares acogen buen número de especies, especialmente en los casos de Garralda y Pikandi. Sin embargo, al contrario de lo que se podía colegir a partir de diferentes estudios (Aramburu, 1996; Aizpurua et al., 1999) la especie puede existir perfectamente sobre sustratos calcáreos, puesto que en las masas de Garralda, dos de los inventarios realizados han constatado una formación relativamente cerrada de roble albar sobre este tipo de sustratos. En todo caso, el que entre en competencia con otras especies como el roble carballo o el haya parece haber relegado al roble albar a aquellas condiciones menos adecuadas por un $\mathrm{pH}$ relativamente ácido o unos suelos magros cuando no prácticamente inexistentes (litosoles).

En lo que respecta a la diversidad específica, Garralda muestra las mejores cifras seguida, muy de cerca, por Pikandi. Garrastatxu se configura como un bosque relativamente pobre en especies, no muy lejos de los hayedos estudiados en este mismo contexto geográfico. Una vez más se vuelven a constatar las notables diferencias, en este caso del cortejo de especies de las tres manchas, cuestión planteada dentro de los objetivos.

Los tres emplazamientos comparten tan solo el $11,4 \%$ de los taxones, lo que habla de la gran diversidad específica de cada uno de los ejemplos y de la dificultad de estimar una formación-tipo; máxime teniendo en cuenta que las especies que se repiten son relativamente ubiquistas y pueden pertenecer a otros bosques y ecosistemas. Esto nos motiva, más si cabe, a seguir estudiando otras manchas de este tipo de bosque y en este contexto geográfico. En cuanto a la originalidad, en Garralda el $64,9 \%$ de sus taxones no aparece en las otras dos ubicaciones, en Pikandi el $40 \%$ y, por último, en Garrastatxu tan solo el 15,4\%. Es posible que la mayor extensión de la mancha de Garralda, unida a que ocupa sustratos más diversificados y con orientaciones relativamente contrastadas, esté dando lugar a una diversidad mayor y a una nómina de especies acompañantes superior en número y diferente a las de las otras dos manchas que cuentan con unas condiciones más homogéneas.

La formación de robledal albar más diversa estructuralmente es la de Pikandi, seguida por la de Garralda y, en último lugar, Garrastatxu. Es posible que la fuerte densidad del dosel arbóreo de Garralda dé lugar a una cierta pobreza en el nivel de cobertura de los estratos inferiores; sin embargo, eso no ocurre en Pikandi, que presenta las mejores coberturas no sólo en el estrato superior, sino también en el arbustivo, sub-arbustivo y herbáceo. También en este aspecto, las comparaciones enunciadas en los objetivos han sido abordadas dando lugar a la constatación de diferencias notables entre las tres localizaciones de estudio.

En cuanto a las adscripciones corológicas de los taxones presentes en los robledales albares estudiados, en los tres casos dominan las componentes eurosiberianas/euroasiáticas, atlánticas y las de transición entre lo atlántico y lo mediterráneo. Sumadas las dos primeras, las tres ubicaciones presentan porcentajes muy altos (70\% en Pikandi, $65 \%$ en Garralda y $57 \%$ en Garrastatxu). Las de amplio rango territorial muestran porcentajes globales no superiores al 25\%; ello atestigua la calidad de los taxones, que se acrecienta con 
la aportación de endemismos y taxones orófitos boreal-alpinos y alpino-pirenaicos. Todo ello hace, por una parte, que no se sostengan aquellas afirmaciones que hablan del robledal de roble albar como ubicado, de forma óptima, dentro de un contexto transicional entre el mundo atlántico y el mediterráneo (Aramburu, 1996). Al contrario, la mayor parte de su cortejo responde a especies de filiación eurosiberiana o atlántica. Además de esto, la escasez de taxones de amplia distribución (subcosmopolitas, plurirregionales o circumboreales) y la existencia de otros susceptibles de una protección más o menos estricta (endemismos y orófitos) hace que estas masas deban ser protegidas de forma activa.

El estatus de las diversas especies muestra un único taxón muy raro en Garralda, dos raros en esta localidad y Pikandi, y ninguno muy raro o raro en Garrastatxu. En los tres casos existe, eso sí, un importante número de taxones escasos, lo que, sumado a lo anterior, habla de la necesidad de tenerlos en cuenta a la hora de poner en marcha medidas de protección y correcta gestión. En este sentido, Garrastatxu y Pikandi se ubican en sendos parques naturales (Gorbea y Aizkorri-Aratz), cosa que no ocurre con Garralda, que es acreedora de medidas de protección superiores a las hoy día existentes. También en este sentido se ha cumplido otro de los objetivos de la investigación como es la evaluación biogeográfica para hacer propuestas de protección y correcta gestión de estas masas. Se podría abogar por añadir, a parte de la protección derivada de la figura de parque natural, otra que bien podría corresponderse con el de microrreserva o reserva para aquellos enclaves concretos que aglutinen los endemismos y las plantas orófitas. Sin embargo, el Gobierno del País Vasco no incluye dentro de su legislación de protección de la naturaleza (Decreto legislativo 1/2014, de 15 de abril, por el que se aprueba el texto refundido de la Ley de Conservación de la Naturaleza del País Vasco) ninguna de las dos figuras. Sí lo hace la legislación de la Comunidad Foral de Navarra (Ley 42/2007, de 13 de diciembre, del Patrimonio Natural y de la Biodiversidad) que debería ser aplicada a las manchas de robledal de $Q$. petraea.

Los resultados de la aplicación del método de valoración biogeográfica LANBIOEVA también coadyuvan al cumplimiento del objetivo enunciado con anterioridad y arrojan datos bien esclarecedores, tanto en lo concerniente al Interés de Conservación como a la Prioridad de Conservación. Respecto al primero de ellos y en lo que respecta al Interés Natural, el interés fitocenótico del robledal albar puede calificarse de sobresaliente, a la cabeza de todas las agrupaciones forestales del ámbito de estudio (Lozano et al., 2020). Ello deriva de su alto grado de diversidad y naturalidad, circunstancia que se extiende al criterio de madurez y, en menor medida, al de resiliencia. En cuanto al interés territorial, los robledales no son, en general, muy pródigos en elementos raros, endémicos o finícolas; pero estas limitaciones son compensadas con creces en los albares dado su acreditado carácter relíctico. El interés mesológico alcanza cotas verdaderamente punteras en todos y cada uno de los ítems que lo integran, destacando claramente sus funciones geomorfológica, edáfica y faunística. El interés estructural se presenta algo más comedido, habida cuenta de que esta agrupación vegetal presenta buenos niveles de riqueza y cobertura por estrato, discreta variedad de microhábitats y un grado más que aceptable de conectividad espacial.

Los criterios que conforman el Interés Cultural mantienen la misma tónica. En efecto, tanto en su vertiente patrimonial (etnobotánica, percepcional y didáctica) como estructural (fisionómica y cultural), los robledales albares son pródigos en elementos y valores ligados a un determinado manejo tradicional y ancestral por parte del ser humano y que concitan una atención cada día mayor en la sensibilidad y políticas conservacionistas. Con todo ello, el Interés de Conservación, suma del Interés Natural e Interés Cultural, alcanza puntuaciones que los sitúan claramente al frente de las agrupaciones vegetales más estimables de la zona de estudio (Lozano et al., 2020).

Sin embargo, y pese a lo sobresaliente del Interés de Conservación, la Prioridad de Conservación alcanza registros ciertamente contenidos en los robledales albares. Ello se explica por el afortunadamente bajo Factor de Amenaza al que están sometidos, pues su carácter montaraz les hace ubicarse en zonas relativamente alejadas de los núcleos poblacionales, presentar mediocre accesibilidad y transitabilidad, y no ser objeto preferente de amenazas alternativas tales como la invasión de elementos xenófitos o planes de construcción de infraestructuras diversas. Ha de tenerse en cuenta, además, el hecho de que la mayor parte de las manchas de albar se asientan en espacios protegidos, hecho que aleja riesgos y peligros y garantiza un tipo de gestión forestal que prima la función geoecológica sobre la meramente productiva. 
En todo caso, formaciones vegetales tan menguantes como los robledales albares son acreedoras de protección a ultranza, aunque no cuenten, en la actualidad, con presiones o impactos antrópicos importantes. Han de arbitrarse y aplicarse, por tanto, medidas como el control de actividades extractoras y ganaderas que garanticen la preservación de, cuando menos, los rodales mejor conservados, lo que es especialmente imperativo y urgente en el caso de los bosques de Garralda.

La labor investigadora tendrá continuidad en otras localizaciones (Encartaciones vizcaínas, comarca navarra de la Barranca, norte de Navarra...). El estudio de estas manchas puede dar lugar a un conocimiento más profundo y certero de las variables analizadas.

\section{Agradecimientos}

El presente artículo ha podido realizarse gracias al grupo de investigación consolidado de la Universidad del País Vasco/Euskal Herriko Univertsitatea, referencia: Ekopol IT1365-19 del Gobierno Vasco.

\section{Declaración responsable y conflicto de intereses}

Las/os autoras/es declaran que no existe ningún conflicto de interés con relación a la publicación de este artículo. Todos los autores hemos participado, de la misma manera e intensidad, en las etapas de inventariado, procesamiento de datos y redacción del trabajo.

\section{REFERENCIAS}

Aizpurua, I., Aseginolaza, C., Uribe-Echebarría, P.M., Urrutia, P. \& Zorrakin, I. (1999). Claves ilustradas de la Flora del País Vasco y territorios limítrofes. Departamento de Urbanismo Vivienda y Medio Ambiente.

Aramburu, A. (dir. y coord.) (1996). Vegetación de la Comunidad Autónoma del País Vasco. Departamento de Urbanismo Vivienda y Medio Ambiente.

Bennet, K.D., Tzedakis, P.C. \& Willis, K.J. (1991). Quaternary refugia of north European trees. Journal of Biogeography, 18, 103-115. https://doi.org/10.2307/2845248

Blanco, E., Casado, M.A., Costa, M., Escribano, R., García, M., Génova, M., Gómez, A., Gómez, F., Moreno, J.C., Morla, C., Regato, P. \& Sainz, H. (1997). Los bosques ibéricos. Una interpretación geobotánica. Planeta.

Carrión, J.S., Parra, I., Munuera, M. \& Navarro, C. (2000). Past distribution and ecology of the cork oak (Quercus suber) in the Iberian Peninsula: a pollen-analytical approach. Diversity and Distributions, 6, 213-227. https://doi.org/10.1046/ j.1472-4642.2000.00070.x

Gassiot, E., Rodríguez, D., Pèlachs, A., Pérez-Obiol, R., Julià, R., Bal-Serin, M.C. \& Mazzucco, N. (2014). La alta montaña durante la Prehistoria: 10 años de investigación en el Pirineo catalán occidental. Trabajos de Prehistoria, 71 (2), 261281. http://dx.doi.org/10.3989/tp.2014.12134

Gobierno Vasco. (1991). Mapa de vegetación de la Comunidad Autónoma del País Vasco. Departamento de Urbanismo Vivienda y Medio Ambiente. Escala 1:25.000.

Jalut, G. (1988). Les principales etapes de l'histoire de la forêt pyrénénne française depuis 15.000 ans. Monografías del Instituto Pirenaico de Ecología, 4, 609-615.

Kremer, A., Dupoueyb, J.L., Douglas, J., Cottrelld, J., Csaikle, U., Finkeldeyf, R., Espinelg, S., Jensenh, J., Kleinschmiti, J., Van Damj, B., Ducoussoa, A., Forrestd, I., López de Heredia, U., Lowec, A.J., Tutkovae, M., Munroc, R.C., Steinhoffiand, S \& Badeau, V. (2002). Leaf morphological differentiation between Quercus robur and Quercus petraea is stable across western European mixed oak stands. Annals of Forest Science, 59, 777-787. https://doi.org/10.1051/forest:2002065

Loidi, J. (1983). Estudio de la flora y vegetación de las cuencas de los ríos Deva y Urola en la provincia de Guipúzcoa. [Tesis Doctoral, Universidad Complutense].

López, G. (1982). La guía de INCAFO de los árboles y arbustos de la Península Ibérica. INCAFO. 
Lozano, P.J.; Varela, R., Latasa, I., Lozano, A. \& Meaza, G. (2020). Biogeographic assessment of vegetal landascape, at a global scale, trough "LANBIOEVA" methodology (Landscape Biogeographical Evaluation). XXXIV UGI Congress Book.

Muir, G., Fleming, C.C. \& Schlotterer, C. (2001). Three divergent rDNA clusters predates species divergence in Quercus petraea (Matt.) Liebl. And Quercus robur L.Mol. Biol. Evol., 18, 112-119. https://doi.org/10.1093/oxfordjournals.molbev.a003785

Pèlachs, A., Soriano, J.M., Nadal, J. \& Esteban, A. (2007). Holocene environmental history and human impact in the Pyrenees. Contributions to Sciencie, 3 (3), 421-429. https://ddd.uab.cat/record/118003

Pèlachs, A., Julià, R., Pérez-Obiol, R., Soriano, J.M., Bal, M.C., Cunill, R. \& Catalan, J. (2011). Potential influence of Bond events on mid-Holocene climate and vegetation in southern Pyrenees as assessed from Burg lake LOI and pollen records. The Holocene, 21(1), 95-104. https://doi.org/10.1177/0959683610386820

Pèlachs, A., García, J.C., Soriano, J.M., Pérez-Obiol, R. \& Catalán, J. (2016). Papel de los incendios en las dinámicas forestales del Norte de la Península Ibérica durante el Holoceno. En J. Gómez Zotano et. al. (eds.). Avances en Biogeografía. Áreas de distribución: entre puentes y barreras (pp. 553-562). Editorial Universidad de Granada y Tundra ediciones.

Peñalba, M.C. (1994). The history of the Holocene vegetation in northern Spain from pollen analysis. Journal of Ecology, 82, 815-832. https://doi.org/10.2307/2261446

Rivas, S., Bascones, J.C., Díaz, T.E., Fernández, F. \& Loidi, J. (1991). Vegetación del Pirineo occidental y Navarra. Itinera Geobotánica, 5, 5-456.

Sánchez-Goñi, M.F. \& Hannon, G.E. (1999). High-altitude vegetational pattern of the Iberian Mountain Chain (north-central Spain) during the Holocene. The Holocene, 9, 39-57. https://doi.org/10.1191/095968399671230625

Streiff, R., Labbe, T., Bacilieri, R, Steinkellner, H., Glös, J. \& Kremer, A. (1998). Within-population genetic structure in Quercus robur L. and Quercus petraea (Matt.) Liebl. assessed with isozymes and microsatellites. Molecular Ecology, 7, 317328. http://dx.doi.org/10.1046/j.1365-294X.1998.00360.x 